\title{
The effect of yellow pea protein and fibre on short-term food intake, subjective appetite and glycaemic response in healthy young men
}

\author{
Christopher E. Smith, Rebecca C. Mollard, Bohdan L. Luhovyy and G. Harvey Anderson* \\ Department of Nutritional Sciences, Faculty of Medicine, University of Toronto, 150 College Street, Room 322, Toronto, \\ ON, Canada M5S 3E2
}

(Submitted 25 July 2011 - Final revision received 30 November 2011 - Accepted 1 December 2011)

\begin{abstract}
Pulses are low-glycaemic foods rich in protein (20-25\%), resistant starch and fibre that suppress appetite and glycaemia. The objective of the present study was to elucidate the component(s) of yellow peas responsible for these benefits and assess their efficacy as value-added food ingredients. We investigated the effects of 10 or $20 \mathrm{~g}$ of isolated yellow pea protein (P10 and P20) or fibre (F10 and F20) on food intake (FI) at an ad libitum pizza meal served at $30 \mathrm{~min}$ (Expt 1, $n$ 19) or $120 \mathrm{~min}$ (Expt 2, $n$ 20) and blood glucose (BG) and appetite in young, healthy males (20-30 years). In Expt 1, P20 led to lower FI than control (4937 (SEM 502) v. 5632 (SEM 464 ) kJ (1180 (SEM 120) v. $1346(\operatorname{sem~111)~kcal))~and~all~other~treatments~}(P<0 \cdot 01)$ and lower cumulative FI (pizza meal kcal + treatment kcal; CFI) compared to F10 (5460 (SEM 498) v. 6084 (SEM 452) kJ (1305 (SEM 119) v. 1454 (sEm 108) kcal); $P=0 \cdot 033$ ). Both protein treatments suppressed mean pre-meal $(0-30 \mathrm{~min})$ BG compared to control $(P<0 \cdot 05)$, whereas only P20 suppressed mean post-meal $(50-120 \mathrm{~min})$ BG $(P<0 \cdot 01)$. There was no effect of treatment on pre-meal or post-meal appetite. In Expt 2, there was no effect of treatment on FI, CFI, or pre- or post-meal BG or appetite. In conclusion, protein is the component responsible for the short-term effects of yellow peas in the regulation of glycaemia and FI, but its second-meal effects disappear by $2 \mathrm{~h}$ post-consumption.
\end{abstract}

Key words: Yellow pea fractions: Food intake regulation: Appetite: Blood glucose control

The emergence of the current obesity pandemic has been accompanied by a concomitant increase in related morbidities, especially metabolic syndrome and diabetes mellitus ${ }^{(1)}$. This has made it increasingly important to discover and develop foods, or functional food ingredients, that suppress food intake (FI) and improve metabolic regulation. Foods, or food ingredients, that suppress appetite and FI have the potential to correct the chronic energy imbalance that leads to obesity, thus offering an inexpensive and safe alternative to other obesity treatments such as pharmaceuticals or surgery.

Pulses, the edible seeds of pod-bearing leguminous plants including chickpeas, lentils, beans and yellow peas, have a low glycaemic index and are very high in protein and dietary fibre which are more satiating than other macronutrients ${ }^{(2-4)}$. Epidemiological studies have consistently shown an association between consumption of pulses and reduced risk of obesity, diabetes mellitus and components of metabolic syndrome ${ }^{(5-7)}$.

Pulses are also reported to have significant short-term physiological benefits. When consumed alone or as part of a mixed-macronutrient meal, pulses suppress appetite and blood glucose (BG) not only to the meal, but also following a subsequent meal served up to $4 \mathrm{~h} \operatorname{later}^{(8)}$ (R. C. Mollard et al., unpublished results). Although the health benefits associated with pulse consumption are well documented, the component, or components, responsible for their effects has not been investigated. This led us to investigate the isolated fibre and protein fractions of yellow peas to determine if these components are responsible for the observed beneficial effects on the glycaemic response and weight management of whole pulses. Yellow peas (Pisum sativum) were chosen because despite being among the least expensive and most abundant non-oilseed pulses, their consumption in the countries with the highest rates of overweight and obesity (mostly North American and European markets) is extremely low ${ }^{(9)}$. Yellow peas are also safe and inexpensive; and high-quality, food-grade fibre and protein fractions are commercially available and approved for human consumption.

The hypothesis of the present study was that the suppression of short-term FI, appetite and BG after consumption of whole yellow peas is due, at least in part, to their protein

Abbreviations: BG, blood glucose; CFI, cumulative food intake; F10, $10 \mathrm{~g}$ of isolated yellow pea fibre; F20, $20 \mathrm{~g}$ of isolated yellow pea fibre; FI, food intake; $\mathrm{P} 10,10 \mathrm{~g}$ of isolated yellow pea protein; P20, $20 \mathrm{~g}$ of isolated yellow pea protein; VAS, visual analogue scales; WI, water intake. 
and fibre fractions. Therefore, the objective of the present study was to investigate the effects of isolated yellow pea protein and fibre, given individually, on short-term FI 30 and $120 \mathrm{~min}$ later as well as subjective appetite, and glycaemic response in young, healthy men. Furthermore, this study provides an insight into the efficacy of yellow pea fractions as value-added ingredients aimed at suppressing FI and controlling BG response.

\section{Experimental methods}

\section{Subjects}

Healthy male participants 20-30 years of age with a BMI of $20 \cdot 0-24.9 \mathrm{~kg} / \mathrm{m}^{2}$ were recruited via advertisements placed about the University of Toronto, Saint George campus, in local newspaper classifieds and on student websites. Females, smokers, breakfast skippers and those on medication, with metabolic disorders or scoring greater than or equal to 11 on an Eating Habits Questionnaire ${ }^{(10)}$ were excluded from the study. This study was conducted according to the guidelines laid down in the Declaration of Helsinki and all procedures involving human subjects/patients were approved by the University of Toronto Health Sciences Research Ethics Board. Written informed consent was obtained from all subjects.

\section{Experimental design}

Two experiments were conducted in which FI was measured at $30 \mathrm{~min}$ (Expt 1) and at $120 \mathrm{~min}$ (Expt 2) after consumption of the treatments. Both experiments were single-blind, randomised, repeated-measures designs in which subjects received one treatment per week, 1 week apart.

\section{Treatments}

The same five treatments were used in both Expt 1 and 2 and were as follows: tomato soup (control) with either $10 \mathrm{~g}$ (F10) or $20 \mathrm{~g}$ (F20) yellow pea fibre or $10 \mathrm{~g}$ (P10) or $20 \mathrm{~g}$ (P20) of yellow pea protein added. Commercially available yellow pea protein and fibre, by the trade names Propulse ( $82 \%$ protein dry weight) and Centara5 (94\% fibre dry weight from yellow pea hulls), respectively, were provided by Nutri-Pea Limited. The protein fraction is isolated from the cotyledon, whereas the fibre is made from yellow pea hulls and contains approximately $85 \%$ insoluble and 15\% soluble fibre (Nutri-Pea Limited, Personal communication). The F10 and F20 treatments contained 10.6 and $21.3 \mathrm{~g}$ of the pea fibre isolate, respectively, to yield 10 and $20 \mathrm{~g}$ of net fibre. Similarly, the P10 and P20 treatments contained 12.2 and $24.4 \mathrm{~g}$ of pea protein isolate, respectively, to yield 10 or $20 \mathrm{~g}$ of pea protein. The control was a tomato soup with no added fractions. All treatments were isovolumetric $(300 \mathrm{ml})$ and contained the following ingredients: tomato paste $(55 \mathrm{~g})$, pepper $(0.6 \mathrm{ml}$, Verona), garlic herbs $(2.5 \mathrm{ml}$, McCormick Garlic and Herb Seasoning), Worcestershire sauce $(2.5 \mathrm{ml}$, Lea \& Perrins), dried basil (0.6 ml, McCormick Canada, Inc.),
Tabasco sauce $(0.25 \mathrm{ml}$, Mcllhenny Company) and lemon juice ( $1.2 \mathrm{ml}$, Canada Dry Mott's). The Na content of a meal has been linked to altered postprandial satiety and glycaemia $^{(11,12)}$. Na content, determined using a modified version of AOAC International method 985.01, was highest in the P20 treatment (294 mg) and thus 570.8, 454.9, 338.0 and $285.4 \mathrm{mg}$ of salt (Sifto Table Salt, Sifto Canada Corp., Mississauga, Ontario, Canada) was added to the control, F10, F20 and P10 treatments, respectively, to equalise their Na content and eliminate any confounded effects of $\mathrm{Na}$. The treatments were prepared $20 \mathrm{~min}$ before the scheduled arrival of the subjects and $85^{\circ} \mathrm{C}$ water was added upon their arrival to make up a total treatment volume of $300 \mathrm{ml}$. All treatments were served with $100 \mathrm{ml}$ of bottled water as palate cleansers. The order of treatments was determined via random number generator for each subject. The nutritional composition of the five treatments is given in Table 1.

\section{Protocol}

As described previously ${ }^{(13,14)}$, subjects were asked to pick a time between 10.00 and 13.00 hours and a day of the week when they wished to begin each of their sessions. Before each session, subjects fasted for $10-12 \mathrm{~h}$ overnight, after which they consumed a standardised breakfast consisting of $26 \mathrm{~g}$ of Honey Nut Cheerios cereal (General Mills), $250 \mathrm{ml}$ of Beatrice 2\% milk (Parmalat Canada) and $250 \mathrm{ml}$ Tropicana orange juice (Tropicana Products, Inc.). A $500 \mathrm{ml}$ bottle of water was also provided to be consumed between breakfast and $2 \mathrm{~h}$ before the start of their session, after which no food or drink was to be consumed. Subjects were asked to abstain from caffeine and alcohol the night before their sessions and to maintain their normal routine of FI and physical activity.

Upon arrival in the lab for each session, subjects completed a Sleep Habits and Stress Factors questionnaire and a Food Intake and Activity Questionnaire in order to assess their compliance with fasting and physical activity instructions. Sessions were rescheduled if any irregularities were found that might have altered the subject's appetite or metabolism. Subjects then completed the baseline $(0 \mathrm{~min})$ visual analogue scales (VAS) to measure motivation to eat (to quantify

Table 1. Nutritional composition of tomato soup treatments

\begin{tabular}{|c|c|c|c|c|c|}
\hline & \multicolumn{5}{|c|}{ Treatment* } \\
\hline & $\mathrm{C}$ & F10 & F20 & P10 & P20 \\
\hline Energy (kJ) & $177 \cdot 8$ & $186 \cdot 2$ & $194 \cdot 6$ & 382.0 & $586 \cdot 2$ \\
\hline Fat $(\mathrm{g})$ & 0.2 & 0.2 & 0.2 & 0.2 & 0.2 \\
\hline Protein $(\mathrm{g})$ & $2 \cdot 1$ & 2.4 & $2 \cdot 7$ & $12 \cdot 1$ & $22 \cdot 1$ \\
\hline $\begin{array}{l}\text { Available } \\
\text { carbohydrate }(\mathrm{g}) \dagger\end{array}$ & 9.5 & $10 \cdot 0$ & $10 \cdot 5$ & 9.5 & 9.5 \\
\hline Fibre (g) & $2 \cdot 0$ & $12 \cdot 0$ & $22 \cdot 0$ & $2 \cdot 0$ & $2 \cdot 0$ \\
\hline $\mathrm{Na}(\mathrm{mg})$ & 294.2 & 294.2 & 294.2 & 294.2 & 294.2 \\
\hline
\end{tabular}

C, control; F10, $10 \mathrm{~g}$ fibre; F20, $20 \mathrm{~g}$ fibre; $\mathrm{P} 10,10 \mathrm{~g}$ protein; $\mathrm{P} 20,20 \mathrm{~g}$ protein.

*Energy content and composition of common ingredients provided by the manufacturer. Composition of yellow pea fractions determined using the following methods: fat, AOAC 983.23; protein, AOAC 992.15; fibre, AOAC 43-A14; $\mathrm{Na}$ AOAC 985.01. Amounts given are per $300 \mathrm{ml}$ serving.

†Calculated as (total carbohydrate - fibre). 
subjective appetite), thirst, physical comfort, and energy and fatigue. VAS consist of a $100 \mathrm{~mm}$ printed line anchored to opposing statements on either side. Subjects were informed to place an ' $\mathrm{X}$ ' on the line at a location that reflects their level of agreement with the two statements. The VAS were scored by measuring the distance, in $\mathrm{mm}$, from the leftmost statement to the intersection of the marked ' $\mathrm{X}$ '. This allowed for the accurate measurement of variables on a continuum instead of discrete categories to which the subjects' feelings may not correspond. The utility of VAS for measuring subjective appetite has previously been validated in children as well as adults ${ }^{(15,16)}$.

A baseline BG measurement was then taken via finger prick using a Monojector lancet (Sherwood Medical) and capillary BG measured and converted to plasma glucose equivalent using an Accu-check Compact-Plus glucose monitor (Roche Diagnostics Canada). A baseline measurement of greater than $5.5 \mathrm{mmol} / 1$ suggested non-compliance with the fasting instructions and subjects were rescheduled accordingly. As per the manufacturer's instructions, the first drop of blood was wiped away and the second drop placed on the testing strip. Subjects were assigned specific glucose monitors and testing strip batch codes for the duration of the study. Quality control measurements using two concentrations (6.3 and $10.0 \mathrm{mmol} / \mathrm{l}$ ) of Assayed Human Multi-Sera (Randox Laboratories Limited) were performed before each session to ensure that glucose monitors and test strips were within an acceptable range of accuracy.

Following the completion of the baseline measurements, subjects were given $5 \mathrm{~min}$ to consume their treatment, along with $100 \mathrm{ml}$ of bottled water to cleanse their palate. VAS measuring treatment palatability were then filled out to ensure that appetite and FI were not affected by the subject's dislike of a treatment. The palatability VAS consisted of three questions assessing the pleasantness, taste and texture of the treatments. In Expt 1, BG (via finger prick), subjective appetite, physical comfort and energy fatigue (via VAS) were measured at 15 and 30 (pre-meal) as well as at 50, 65, 80, 95, 110, 140 and $170 \mathrm{~min}$ (post-meal) after consumption of the treatment. In Expt 2, the same outcomes were measured at 15, 30, 45, 60, 90 and $120 \mathrm{~min}$ (pre-meal) as well as 140, 155, 170, 185 and $200 \mathrm{~min}$ (post-meal) after consumption of the treatments.

FI was measured at 30 (Expt 1) or $120 \mathrm{~min}$ (Expt 2) after consumption of the treatments. Subjects were instructed to eat until 'comfortably full' and given 20 min during which time they were served an ad libitum pizza meal consisting of McCain Deep 'N Delicious (McCain Foods Canada) pizzas, prepared, as suggested by the manufacturer, by baking for $8 \mathrm{~min}$ in a $221^{\circ} \mathrm{C}$ oven, along with ad libitum bottled water. Pepperoni, Three cheese and Deluxe pizzas were served, four at a time, with two pizzas of their first choice as determined during screening, and one each of the others. A fresh batch of four pizzas was served every $7 \mathrm{~min}$ and water was given as needed. FI and water intake (WI) was measured by weighing the cooked pizza and bottled water before and after the meal without the subjects' knowledge. The manufacturers' nutritional information was used to calculate energy intake in $\mathrm{kJ}$. The three varieties of pizza averaged $10.0 \mathrm{~g}$ of protein, $7.6 \mathrm{~g}$ of fat, $26.6 \mathrm{~g}$ of carbohydrate and $945.6 \mathrm{~kJ} / 100 \mathrm{~g}$. Following the pizza meal, subjects filled out a VAS measuring the palatability of the pizza meal.

\section{Data analysis}

Average subjective appetite was calculated as the average of the four questions on the Motivation to Eat VAS as follows: Average appetite score $=($ desire to eat + hunger $+(100-$ fullness $)$ + prospective consumption) $/ 4$. Average treatment palatability was calculated as the average of the three questions on the treatment palatability VAS as follows: (pleasantness + taste + texture) $/ 3$.

All statistical analyses were conducted using the SAS version 9.2 (Statistical Analysis Systems; SAS Institute, Inc.) software suite. In the study, two-way repeated-measures ANOVA tests were used to test for treatment, time and treatment-by-time interaction effects on glycaemic response, subjective appetite, physical comfort, and energy and fatigue. For variables with a significant treatment and/or interaction effect $(P<0.05)$, one-way repeated-measures ANOVA and Tukey-Kramer's post hoc test were used to determine between-treatment differences at individual time points. Treatment effects on the following variables were tested via one-way repeated-measures ANOVA: food and WI; and treatment and pizza palatability.

Correlation analyses among treatments and outcome measures were performed using the Pearson's Correlation Coefficient. All results are presented as means with their standard errors of the mean. Statistical significance was concluded with the $P$-value less than $0 \cdot 05$.

Table 2. Energy intake and cumulative energy intake at the ad libitum pizza meal

(Mean values with their standard errors, $n 19$ in Expt 1, $n 20$ in Expt 2)

\begin{tabular}{|c|c|c|c|c|}
\hline \multirow[b]{2}{*}{ Treatment } & \multicolumn{2}{|c|}{ Food intake $(\mathrm{kJ})^{\star}$} & \multicolumn{2}{|c|}{$\begin{array}{l}\text { Cumulative energy } \\
\text { intake }(\mathrm{kJ}) \dagger\end{array}$} \\
\hline & Mean & SEM & Mean & SEM \\
\hline \multicolumn{5}{|l|}{ Expt 1} \\
\hline C & $5633 \cdot 2^{a}$ & $463 \cdot 9$ & $5811 \cdot 0^{\mathrm{a}, \mathrm{b}}$ & 463.9 \\
\hline F10 & $5894.9^{a}$ & $454 \cdot 3$ & $6081 \cdot 1^{\mathrm{a}}$ & $454 \cdot 3$ \\
\hline F20 & $5832 \cdot 8^{\mathrm{a}}$ & 471.0 & $6027 \cdot 3^{a, b}$ & 471.0 \\
\hline P10 & $5677 \cdot 9^{\mathrm{a}}$ & 398.3 & $6059 \cdot 9^{\mathrm{a}, \mathrm{b}}$ & $398 \cdot 3$ \\
\hline P20 & $4938.0^{b}$ & $500 \cdot 7$ & $5524 \cdot 1^{\mathrm{b}}$ & $500 \cdot 7$ \\
\hline$P$ & \multicolumn{2}{|c|}{0.0008} & \multicolumn{2}{|c|}{0.0338} \\
\hline \multicolumn{5}{|l|}{ Expt 2} \\
\hline C & 6090.5 & 365.2 & $6268 \cdot 3$ & 365.2 \\
\hline F10 & $6127 \cdot 4$ & $360 \cdot 1$ & 6313.5 & $360 \cdot 1$ \\
\hline F20 & 6403.9 & 443.7 & 6598.5 & $443 \cdot 7$ \\
\hline P10 & 5819.9 & 384.8 & 6201.9 & 384.8 \\
\hline P20 & $6015 \cdot 6$ & 374.4 & $6601 \cdot 8$ & 374.4 \\
\hline$P$ & \multicolumn{2}{|c|}{0.4521} & \multicolumn{2}{|c|}{0.4095} \\
\hline
\end{tabular}

C, control; F10, $10 \mathrm{~g}$ fibre; F20, $20 \mathrm{~g}$ fibre; P10, $10 \mathrm{~g}$ protein; P20, $20 \mathrm{~g}$ protein.

${ }^{a}, \mathrm{~b}$ Mean values within a column with unlike superscript letters were significantly different from each other $(P<0.05$, one-way ANOVA, Tukey-Kramer post hoc test).

* Energy consumption in a test meal was measured at 30 min in Expt 1 and 120 min in Expt 2 following treatments.

†Energy from treatment + energy from test meal. 
Table 3. Mean blood glucose during the pre- and post-meal periods in Expt 1 and 2

(Mean values with their standard errors, $n 19$ in Expt 1, $n 20$ in Expt 2)

\begin{tabular}{|c|c|c|c|c|}
\hline \multirow[b]{2}{*}{ Treatment } & \multicolumn{2}{|c|}{ Pre-meal $(\mathrm{mmol} / \mathrm{l})^{*}$} & \multicolumn{2}{|c|}{ Post-meal $(\mathrm{mmol} / \mathrm{l}) \dagger$} \\
\hline & Mean & $\overline{\text { SEM }}$ & Mean & $\overline{\text { SEM }}$ \\
\hline \multicolumn{5}{|l|}{ Expt 1} \\
\hline $\mathrm{C}$ & $5 \cdot 31^{a}$ & 0.11 & $6 \cdot 23^{a}$ & 0.09 \\
\hline F10 & $5 \cdot 12^{a, b}$ & 0.07 & $6 \cdot 37^{\mathrm{a}}$ & 0.09 \\
\hline $\mathrm{F} 20$ & $5.06^{a, b}$ & 0.06 & $6 \cdot 07^{a, b}$ & 0.07 \\
\hline P10 & $4.95^{\mathrm{b}}$ & 0.07 & $6 \cdot 07^{a, b}$ & 0.09 \\
\hline P20 & $5 \cdot 05^{\mathrm{b}}$ & 0.06 & $5 \cdot 95^{\mathrm{b}}$ & 0.09 \\
\hline$P$ & \multicolumn{2}{|c|}{0.0253} & \multicolumn{2}{|c|}{$<0.0001$} \\
\hline \multicolumn{5}{|l|}{ Expt 2} \\
\hline $\mathrm{C}$ & 5.03 & 0.04 & $6 \cdot 10$ & 0.09 \\
\hline F10 & 4.97 & 0.04 & $6 \cdot 13$ & 0.09 \\
\hline F20 & 5.07 & 0.04 & 6.35 & 0.10 \\
\hline P10 & 5.08 & 0.04 & $6 \cdot 31$ & 0.10 \\
\hline P20 & 5.01 & 0.04 & 6.09 & 0.08 \\
\hline$P$ & \multicolumn{2}{|c|}{0.6691} & \multicolumn{2}{|c|}{0.0342} \\
\hline
\end{tabular}

C, control; F10, $10 \mathrm{~g}$ fibre; F20, $20 \mathrm{~g}$ fibre; P10, $10 \mathrm{~g}$ protein; P20, $20 \mathrm{~g}$ protein.

${ }^{a, b}$ Mean values within a column with unlike superscript letters were significantly different from each other for the same experiment $(P<0.05$, two-way ANOVA, Tukey-Kramer post hoc test).

* Pre-meal values are means of all observations before the test meal: 0,15 and 30 min in Expt 1 and 0, 15, 30, 45, 60, 90 and 120 min in Expt 2.

† Post-meal values are means of all observations after the test meal: 50, 65, 80, 95, 110, 140 and 170 min in Expt 1 and 140, 155, 170, 185 and 200 min in Expt 2.

\section{Results}

\section{Subject characteristics}

In Expt 1 , nineteen subjects were recruited with a mean age of 23.2 (sem 0.5 ) years and BMI of 22.5 (sem 0.3 ) $\mathrm{kg} / \mathrm{m}^{2}$. In Expt 2, twenty subjects were recruited with a mean age of 22.3 (SEM 0.5 ) years and BMI of $21 \cdot 8($ SEM $0 \cdot 3) \mathrm{kg} / \mathrm{m}^{2}$.

\section{Food and water intake}

In Expt 1, there was a significant effect of treatment on FI at $30 \mathrm{~min}(P=0 \cdot 0008)$. FI following P20 was lower compared to all other treatments $(P<0.05)$. No other differences between the treatments were found (Table 2). Cumulative FI (CFI), the sum of energy consumed at the treatment and at the pizza meal, was also significantly affected by treatment $(P=0 \cdot 03)$. CFI was suppressed by $\mathrm{P} 20$ compared to $\mathrm{F} 10$ $(P=0.03)$; all other treatments led to intermediate CFI. WI was not affected by treatment $(P=0.92)$.

In Expt 2, there was no effect of treatment on FI $(P=0 \cdot 45)$, CFI $(P=0 \cdot 41)$ or WI $(P=0 \cdot 40)$ at $120 \mathrm{~min}$ (Table 2$)$.

\section{Blood glucose}

In Expt 1, pre-meal mean BG (0, 15 and $30 \mathrm{~min})$ was significantly affected by time $(P<0.0001)$ and treatment $(P=0.02)$, but not by their interaction $(P=0 \cdot 28)$. Over the entire premeal period, BG was lower following both protein treatments compared to control $(P<0 \cdot 05$; Table 3$)$. BG was lowest upon arrival at the lab and gradually increased following the treatment until $30 \mathrm{~min}$. BG at $15 \mathrm{~min}$ was lower following P10 compared to control ( $P=0.03$; Fig. 1(A)). Post-meal $(50,65$, $80,95,110,140$ and $170 \mathrm{~min}) \mathrm{BG}$ was significantly affected by time $(P<0 \cdot 0001)$, treatment $(P=0 \cdot 001)$ and their interaction $(P<0.0001)$; the latter of which is explained by variable treatment effects over time. Overall post-meal BG was suppressed following P20 compared to control and F10 $(P<0.05$; Table 3). BG was highest at $65 \mathrm{~min}$ ( $15 \mathrm{~min}$ following completion of the meal) and gradually declined until the end of the study period. BG immediately following the pizza meal (50 min) was lower following both doses of protein compared to that after the control and F10 $(P<0 \cdot 0001)$ (Fig. 1(A)). BG at 50 min following P20 was also lower than after F20 $(P<0 \cdot 0001)$. At $65 \mathrm{~min}, \mathrm{BG}$ was lower following $\mathrm{P} 20$ compared to that after the control and both fibre treatments $(P<0 \cdot 0001)$, while P10 resulted in intermediate BG.

In Expt 2, mean pre-meal BG over time (0, 15, 30, 45, 60, 90 and $120 \mathrm{~min})$ was significantly affected by time $(P<0.0001)$, but not treatment $(P=0.67)$ or treatment-by-time interaction $(P=0 \cdot 16)$ (Table 3). Pre-meal BG was lowest at baseline, increased slightly to $30 \mathrm{~min}$ and then returned to baseline before $120 \mathrm{~min}$. There was an effect of time $(P<0 \cdot 0001)$ and treatment $(P=0.03)$, but no effect of treatment-by-time interaction $(P=0 \cdot 17)$ on post-meal $(140,155,170,185$ and $200 \mathrm{~min}$ ) BG (Fig. 1(B)). BG peaked at $155 \mathrm{~min}$, regardless of treatment and declined steadily until $200 \mathrm{~min}$, without
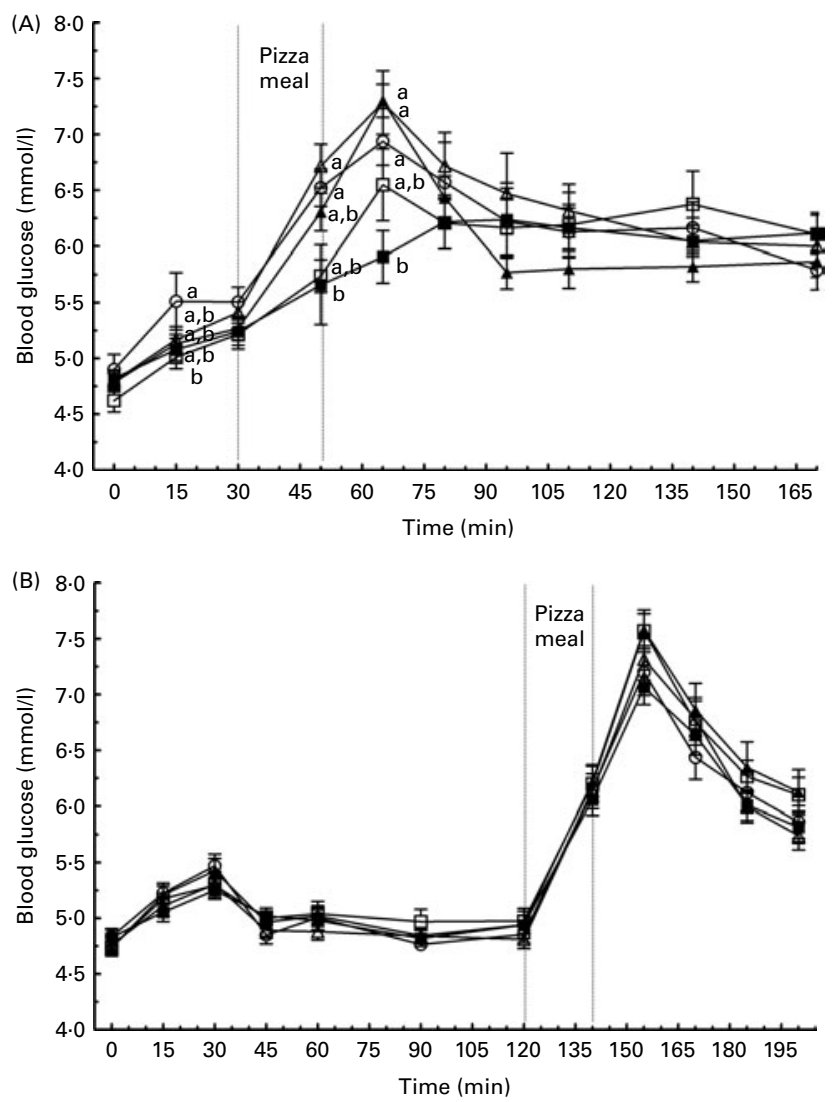

Fig. 1. Effect of treatments on blood glucose concentrations over time (A) Expt 1. (B) Expt 2. Treatments were served in a tomato soup with 10

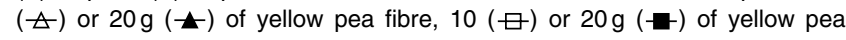
protein, or a control (๑) with no added fractions. Values are means, with their standard errors represented by vertical bars ( $n 19$ in Expt $1 ; n 20$ in Expt 2). ${ }^{a, b}$ Mean values with unlike letters were significantly different at each measured time $(P<0.05$, one-way ANOVA, Tukey-Kramer post hoc test). 
reaching baseline. Although there was a significant treatment effect, Tukey-Kramer's post hoc test did not declare any differences between treatments at any time point (Fig. 1(B)).

\section{Subjective appetite}

In Expt 1, the average of pre-meal appetites was significantly affected by time $(P<0.0001)$, but not treatment $(P=0.42)$ or treatment-by-time interaction $(P=0.58)$ (Table 4$)$. Pre-meal appetite was highest at baseline and dropped slightly after the treatment (Fig. 2(A)). Post-meal appetite was significantly affected by time $(P<0 \cdot 0001)$, but not treatment $(P=0 \cdot 17)$ or their interaction $(P=0.54)$. Post-meal appetite dropped immediately post-meal and slowly rose until the end of the study period. There were no differences between any of the treatments at any time point pre- or post-meal (Fig. 2(A)).

In Expt 2, there was a significant effect of time $(P<0.0001)$, but not of treatment $(P=0 \cdot 37)$ or treatment-by-time interaction $(P=0.81)$ on pre-meal appetite (Table 4$)$. Pre-meal appetite was high at baseline, dropped slightly after the treatment, followed by a slow rise to above baseline at $120 \mathrm{~min}$ (Fig. 2(B)). Post-meal subjective appetite was also affected by time $(P<0.0001)$, but not by treatment $(P=0.58)$ or time-bytreatment interaction $(P=0 \cdot 21)$. Post-meal subjective appetite was lowest immediately following the meal and gradually rose until $200 \mathrm{~min}$. There were no differences between any of the treatments at any time point pre- or post-meal (Fig. 2(B)).

\section{Palatability}

Average palatability ((pleasantness + taste + texture $) / 3$ ) of treatments varied in both experiments, with the ratings for the F20 treatment being significantly lower compared to control

Table 4. Overall mean average appetite scores for the pre- and postmeal periods in Expt 1 and 2

(Mean values with their standard errors)

\begin{tabular}{|c|c|c|c|c|}
\hline \multirow[b]{2}{*}{ Treatment } & \multicolumn{2}{|c|}{ Pre-meal $(\mathrm{mmol} / \mathrm{l})^{\star}$} & \multicolumn{2}{|c|}{ Post-meal $(\mathrm{mmol} / \mathrm{l}) \dagger$} \\
\hline & Mean & SEM & Mean & SEM \\
\hline \multicolumn{5}{|l|}{ Expt 1} \\
\hline C & 65.74 & $2 \cdot 51$ & $27 \cdot 28$ & 1.71 \\
\hline F10 & 68.90 & $2 \cdot 10$ & 29.50 & 1.69 \\
\hline F20 & 64.90 & 2.55 & 32.43 & 1.63 \\
\hline P10 & 65.80 & $2 \cdot 20$ & $27 \cdot 63$ & 1.65 \\
\hline P20 & 62.44 & $2 \cdot 87$ & $30 \cdot 02$ & 1.62 \\
\hline$P$ & \multicolumn{2}{|c|}{0.2711} & \multicolumn{2}{|c|}{0.1682} \\
\hline \multicolumn{5}{|l|}{ Expt 2} \\
\hline C & $70 \cdot 72$ & 1.23 & $26 \cdot 90$ & 2.39 \\
\hline F10 & $66 \cdot 11$ & 1.49 & $26 \cdot 15$ & $2 \cdot 31$ \\
\hline F20 & $69 \cdot 28$ & 1.28 & $28 \cdot 11$ & $2 \cdot 38$ \\
\hline P10 & 66.92 & 1.34 & $28 \cdot 39$ & $2 \cdot 25$ \\
\hline P20 & 67.01 & 1.40 & $28 \cdot 19$ & 2.35 \\
\hline$P$ & \multicolumn{2}{|c|}{0.3664} & \multicolumn{2}{|c|}{0.5762} \\
\hline
\end{tabular}

C, control; F10, $10 \mathrm{~g}$ fibre; F20, $20 \mathrm{~g}$ fibre; $\mathrm{P} 10,10 \mathrm{~g}$ protein; $\mathrm{P} 20,20 \mathrm{~g}$ protein.

${ }_{a, b}$ Mean values within a column with unlike superscript letters were significantly different from each other for the same experiment $(P<0.05$, two-way ANOVA, Tukey-Kramer post hoc test).

*Pre-meal values are means of all observations before the test meal: 0,15 and $30 \mathrm{~min}$ in Expt 1 and 0, 15, 30, 45, 60, 90 and 120 min in Expt 2.

†Post-meal values are means of all observations after the test meal: 50, 65, 80, 95, 110,140 and 170 min in Expt 1 and 140, 155, 170, 185 and 200 min in Expt 2.
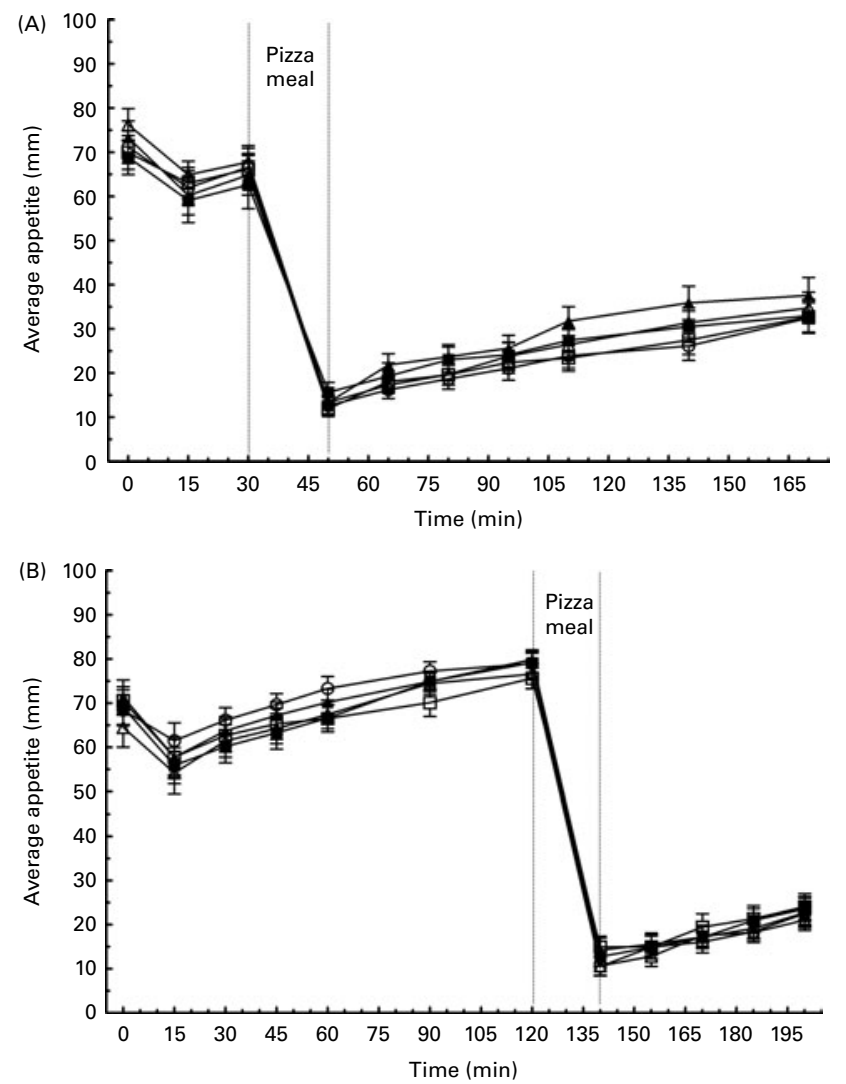

Fig. 2. Effect of treatments on average appetite over time. (A) Expt 1. (B) Expt 2. Treatments were served in a tomato soup with $10(\Delta)$ or $20 \mathrm{~g}\left(\boldsymbol{\Delta}_{-}\right)$ of yellow pea fibre, $10(\square)$ or $20 \mathrm{~g} \mathrm{(} \square)$ of yellow pea protein, or a control (๑) with no added fractions. Values are means, with their standard errors represented by vertical bars ( $n 19$ in Expt $1 ; n 20$ in Expt 2). Mean values with unlike letters were significantly different at each measured time $(P<0.05$, one-way ANOVA, Tukey-Kramer post hoc test).

in both experiments $(P<0 \cdot 05)$. The average palatability of the F10 and P20 treatments was also lower than the control in Expt $2(P<0 \cdot 05)$, but not Expt 1 . Average palatability ratings for the control, F10, F20, P10 and P20 treatments, respectively,

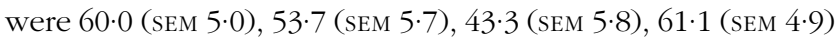
and $51 \cdot 8$ (SEM 5.8) $\mathrm{mm}$ in Expt 1, and 68.4 (SEM 4.2), 53.6 (SEM 4.4), $50 \cdot 4$ (SEM 4.8), 59.8 (SEM 5.4) and 49.2 (SEM 4.9) mM in Expt 2. However, Pearson correlation analysis showed no relationship between treatment palatability and FI at the test meal (Expt 1: $r 0 \cdot 16, P=0 \cdot 13$; Expt $2: r-0 \cdot 13, P=0 \cdot 26)$. Average palatability of the pizza meal was high ( 74.2 (SEM 1.6) mu in Expt $1 ; 80 \cdot 9$ (sEm 1.4) mu in Expt 2) in both experiments and was not affected by the treatments (data not shown).

\section{Discussion}

The results of these studies support a role for yellow pea protein in regulating short-term FI and satiety and glycaemic responses to a second meal. Although the protein preloads did not affect subjective appetite, they led to suppression of FI at $30 \mathrm{~min}$, and reduced the glycaemic response to the treatment as well as the response to the second meal at $30 \mathrm{~min}$, but not at $120 \mathrm{~min}$. Furthermore, yellow pea protein's effects on the pre-meal glycaemic response were independent of dose; 
whereas its effects on the glycaemic response to a second meal and FI at the meal were dose-dependent. These results support the hypothesis that the protein and not the fibre fraction of whole yellow peas is responsible for the physiological effects up to $30 \mathrm{~min}$ after their consumption. However, the effects of the protein fractions are transient and thus the benefits of whole yellow peas beyond $30 \mathrm{~min}$ cannot be explained by their fibre or protein content alone.

The effect of pea protein at $30 \mathrm{~min}$ but not at $120 \mathrm{~min}$ may be explained by the observation that it is both readily digested (plasma amino acid concentrations peak approximately 30 min after consumption) and high in branched-chain amino acids, thus eliciting similar short-term physiological benefits on BG and FI as known for whey ${ }^{(17,18)}$. The suppression of FI by yellow pea protein at $30 \mathrm{~min}$ corresponds with the peak in plasma amino acids following its consumption as well as other proteins with similar digestion kinetics. Whey, a characteristic fast-digesting protein, peaks plasma amino acid concentrations as well as levels of the anorexigenic hormones, insulin and Glucagon-like peptide-1 (GLP-1), between 20 and $40 \mathrm{~min}$ after consumption ${ }^{(18)}$. Calbet \& MacLean $^{(17)}$ found yellow pea protein to affect plasma amino acid and hormone levels in a similar manner as whey. However, plasma amino acid and anorexigenic hormone levels return to baseline well before $120 \mathrm{~min}$ after ingestion of either whey or pea protein ${ }^{(17,18)}$, which may explain the transient nature of pea protein's appetite suppression effects. However, it has been suggested that proteins that are digested quickly and peak plasma amino acids shortly after consumption have synergistic effects on plasma insulin levels when consumed with available carbohydrates ${ }^{(17)}$. Thus, it is possible that the effects of the pea protein may persist past $30 \mathrm{~min}$ if consumed with carbohydrate. Indeed, Manders et $a l .{ }^{(19)}$ found that the insulinaemic response to a glucose drink was 3-fold higher when consumed with a protein hydrolysate mixture ${ }^{(19)}$. In the present study, pea protein was served with very low amounts of available carbohydrates and unfortunately, plasma insulin levels were not measured and thus these hypotheses cannot be assessed, but warrant further investigation.

It is surprising that no effects were detected following the fibre treatments. There are several possible explanations for this. First, the fibre used in the present study was isolated from the hulls of yellow peas. Legume hulls are a byproduct of most processing techniques and contain very high amounts of fibre ${ }^{(20)}$; therefore, the majority of pulse-derived fibre fractions for commercial use are from the hull. However, not only are the hulls much higher in total fibre, but they have very different soluble:insoluble fibre ratios and functional properties $^{(20,21)}$. Dehulling peas reduces the insoluble fibre content of whole peas by $45.8 \%$ and the soluble fibre content by just $21 \cdot 0 \%{ }^{(21)}$. Yellow peas are most commonly consumed dehulled and thus the fibre treatments in the present study may not be representative of the effects of consuming fibre from whole yellow peas. Similar studies are needed to investigate the possible benefits of pea fibre derived from the cotyledon.
Second, our studies to only 120 min may not be of sufficient duration to see the benefits associated with fibre consumption. Many fibres are fermented by bacteria in the large intestine, especially in the caecum and proximal portions of the colon, with beneficial outcomes probably mediated by the production of SCFA ${ }^{(22,23)}$. Indeed, there have been several studies showing short-term metabolic benefits of fermentable fibres. An evening meal including fermentable fibres led to suppressed appetite, FI and BG response to a standardised breakfast the following morning (10.5 h after the evening meal) compared to similar low-fibre meals ${ }^{(23)}$. Furthermore, breath hydrogen, a marker of fermentation, was inversely related to BG response to the morning meal, as well as to GLP-1, indicating that the effects of fibre may have been mediated through changes in the gut microflora and fermentation that require longer than $2 \mathrm{~h}$ to occur.

Lastly, it may be that the amount of yellow pea fibre was not sufficient to exert short-term effects. A study by Samra \& Anderson $^{(24)}$ showed that a high amount of insoluble fibre served in a breakfast cereal reduced glycaemic response to a meal 75 min later. This discrepancy with the present study could be due to the different doses of fibre used $(20 \mathrm{~g} v$. $33 \mathrm{~g}$ ), and because those results were in comparison to highglycaemic index cereal and white bread treatments. A maximum fibre dose of $20 \mathrm{~g}$ was chosen because this is the maximum amount of fibre an individual would normally consume if they ate approximately two servings of whole pulses. Despite the null results of fibre in the present study, further research into the effects of pea fibre is warranted before it can be ruled out as being at least partially responsible for the physiological benefits of whole yellow peas. Studies investigating the cotyledon fibre, larger amounts of fibre and/or a fixed energy test-meal in order to reduce the confounding effects of FI and isolate the effect of fibre on satiety and glycaemic response are needed.

A weakness of the present study was the absence of a treatment containing whole yellow peas. Thus, it is unclear how much of the benefits of whole peas are due to the components. Although protein improved BG and suppressed BG in Expt 1, neither of the yellow pea fractions alone in this study replicated the effects of whole yellow peas on short-term FI, appetite or $\mathrm{BG}^{(8,25,26)}$. This means that not enough of the fractions were used, or perhaps the short-term benefits of whole yellow peas are due to the synergistic effects of these and other components. Yellow peas are also high in resistant starch, which has been associated with improved glycaemic response and suppression of $\mathrm{FI}^{(27-30)}$. Further studies investigating the effects of the starch fraction, as well as with different pea fractions in combination, are required to further understand the mechanism of action of whole pulses.

Nevertheless, this research provides evidence for the efficacy of yellow pea protein as a value-added ingredient in functional foods aimed at suppressing short-term energy intake and BG. More research on the functional properties of yellow pea fractions, as well as on fibre and other fractions, is warranted. 


\section{Conclusion}

In conclusion, protein and not fibre, is the primary component of yellow peas responsible for the suppression of FI and glycaemic response at a meal served at $30 \mathrm{~min}$ after the consumption of whole yellow peas. However, the effects of the protein fraction are transient and thus the benefits of whole yellow peas beyond $30 \mathrm{~min}$ cannot be explained by their fibre or protein content alone.

\section{Acknowledgements}

All the authors contributed to the conceptualisation and design of the present study as well as the writing and review of the paper. C. E. S. conducted the research and analyses. G. H. A. had primary responsibility for the final content. The authors declare no conflict of interest. This work was supported by Agriculture and Agri-Food Canada under the Pulse Research Network (PURENet).

\section{References}

1. World Health Organisation (2006) Obesity and Overweight. http://www.who.int/mediacentre/factsheets/fs311/en/

2. Anderson GH \& Li ET (1987) Protein and amino acids in the regulation of quantitative and qualitative aspects of food intake. Int J Obes 11, Suppl. 3, 97-108.

3. Gerstein DE, Woodward-Lopez G, Evans AE, et al. (2004) Clarifying concepts about macronutrients' effects on satiation and satiety. J Am Diet Assoc 104, 1151-1153.

4. Anderson GH, Aziz A, Abou Samra R, et al. (2006) Physiology of food intake regulation: interaction with dietary components. Nestle Nutr Workshop Ser Pediatr Program 58, 133-143, discussion 143-135.

5. Sichieri R (2002) Dietary patterns and their associations with obesity in the Brazilian city of Rio de Janeiro. Obes Res 10, 42-48.

6. Papanikolaou Y \& Fulgoni VL 3rd (2008) Bean consumption is associated with greater nutrient intake, reduced systolic blood pressure, lower body weight, and a smaller waist circumference in adults: results from the National Health and Nutrition Examination Survey 1999-2002. J Am Coll Nutr 27, 569-576.

7. Cunha DB, de Almeida RM, Sichieri R, et al. (2010) Association of dietary patterns with BMI and waist circumference in a low-income neighbourhood in Brazil. Br J Nutr 104, 908-913.

8. Wong CL, Mollard RC, Zafar TA, et al. (2009) Food intake and satiety following a serving of pulses in young men: effect of processing, recipe, and pulse variety. J Am Coll Nutr 28, 543-552.

9. Schneider AV (2002) Overview of the market and consumption of pulses in Europe. BrJ Nutr 88, Suppl. 3, S243-S250.

10. Velangi A, Fernandes G \& Wolever TM (2005) Evaluation of a glucose meter for determining the glycemic responses of foods. Clin Chim Acta 356, 191-198.

11. Thorburn AW, Brand JC \& Truswell AS (1986) Salt and the glycaemic response. Br Med J (Clin Res Ed) 292, 1697-1699.

12. Driver CJ (1988) The effect of meal composition on the degree of satiation following a test meal and possible mechanisms involved. Br J Nutr 60, 441-449.

13. Anderson GH, Catherine NL, Woodend DM, et al. (2002) Inverse association between the effect of carbohydrates on blood glucose and subsequent short-term food intake in young men. Am J Clin Nutr 76, 1023-1030.

14. Anderson GH, Tecimer SN, Shah D, et al. (2004) Protein source, quantity, and time of consumption determine the effect of proteins on short-term food intake in young men. J Nutr 134, 3011-3015.

15. Flint A, Raben A, Blundell JE, et al. (2000) Reproducibility, power and validity of visual analogue scales in assessment of appetite sensations in single test meal studies. Int J Obes Relat Metab Disord 24, 38-48.

16. Bellissimo N, Thomas SG, Pencharz PB, et al. (2008) Reproducibility of short-term food intake and subjective appetite scores after a glucose preload, ventilation threshold, and body composition in boys. Appl Physiol Nutr Metab 33, 326-337.

17. Calbet JA \& MacLean DA (2002) Plasma glucagon and insulin responses depend on the rate of appearance of amino acids after ingestion of different protein solutions in humans. J Nutr 132, 2174-2182.

18. Nilsson M, Holst JJ \& Bjorck IM (2007) Metabolic effects of amino acid mixtures and whey protein in healthy subjects: studies using glucose-equivalent drinks. Am J Clin Nutr 85, 996-1004.

19. Manders RJ, Wagenmakers AJ, Koopman R, et al. (2005) Co-ingestion of a protein hydrolysate and amino acid mixture with carbohydrate improves plasma glucose disposal in patients with type 2 diabetes. Am J Clin Nutr 82, 76-83.

20. Arrigoni E, Caprez A, Amadò R, et al. (1986) Chemical composition and physical properties of modified dietary fibre sources. Food Hydrocolloids 1, 57-64.

21. Wang N, Hatcher DW \& Gawalko EJ (2008) Effect of variety and processing on nutrients and certain anti-nutrients in field peas (Pisum sativum). Food Chem 111, 132-138.

22. Wong JM, de Souza R, Kendall CW, et al. (2006) Colonic health: fermentation and short chain fatty acids. J Clin Gastroenterol 40, 235-243.

23. Nilsson AC, Ostman EM, Holst JJ, et al. (2008) Including indigestible carbohydrates in the evening meal of healthy subjects improves glucose tolerance, lowers inflammatory markers, and increases satiety after a subsequent standardized breakfast. J Nutr 138, 732-739.

24. Samra RA \& Anderson GH (2007) Insoluble cereal fiber reduces appetite and short-term food intake and glycemic response to food consumed 75 min later by healthy men. Am J Clin Nutr 86, 972-979.

25. Marinangeli CP, Kassis AN \& Jones PJ (2009) Glycemic responses and sensory characteristics of whole yellow pea flour added to novel functional foods. J Food Sci $\mathbf{7 4}$, S385-S389.

26. Marinangeli CP \& Jones PJ (2010) Whole and fractionated yellow pea flours reduce fasting insulin and insulin resistance in hypercholesterolaemic and overweight human subjects. Br J Nutr 1-8.

27. Mikulíková D, Masár S \& Kraic J (2008) Biodiversity of legume health-promoting starch. Starch 60, 426-432.

28. Zhou J, Martin RJ, Tulley RT, et al. (2008) Dietary resistant starch upregulates total GLP-1 and PYY in a sustained daylong manner through fermentation in rodents. Am J Physiol Endocrinol Metab 295, E1160-E1166.

29. Aziz AA, Kenney LS, Goulet B, et al. (2009) Dietary starch type affects body weight and glycemic control in freely fed but not energy-restricted obese rats. J Nutr 139, 1881-1889.

30. Bodinham CL, Frost GS \& Robertson MD (2010) Acute ingestion of resistant starch reduces food intake in healthy adults. Br J Nutr 103, 917-922. 